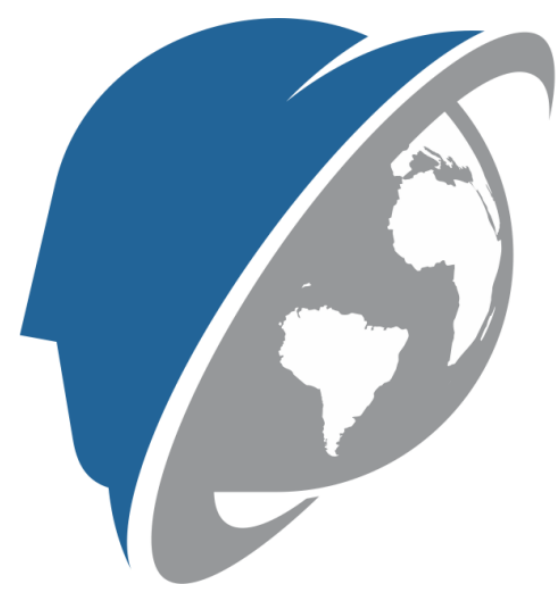

\title{
Open Minds International Journal
}

Open Minds International Journal - ISSN 2675-5157

São Paulo-SP, v. 1, n. 3, setembro-dezembro 2020 https://doi.org/10.47180/omij.v1i3.66 
Open Minds International Journal - Brazil - ISSN 2675-5157

Revista Eletrônica da Editora Mentes Abertas

Editora Mentes Abertas

Luís Murat, 40 - Pinheiros - São Paulo-SP - CEP 05436-050

editor@mentesabertas.com.br

\section{Equipe Editorial}

\section{Editor Chefe}

Prof. Dr. Helder Neves de Albuquerque (Editora Mentes Abertas, Brasil)

\section{Editor Adjunto}

Prof. Me. Jean Carlos da Silva Monteiro (Mentes Abertas, Brasil)

Profa. Mg. Liliana Roxana Rubín (Profesorado Superior de Lenguas Vivas, Argentina)

\section{Conselho Editorial}

Profa. Dra. Eva Paulino Bueno (St. Mary's University, Estados Unidos)

Prof. Dr. Fábio Marques de Souza (UEPB, Brasil)

Prof. Dr. Ivo Di Camargo Junior (SME-Ribeirão Preto - SP, Brasil)

Prof. Dr. Maged Talaat Mohamed Ahmed Elgebaly (Aswan University, Egito)

Profa. Dra. María Isabel Pozzo (IRICE-Conicet-UNR, Argentina)

Profa. Dra. Mona Mohamad Hawi (USP, Brasil)

\section{Conselho Científico (Pareceristas)}

Prof. Dr. Afrânio Mendes Catani (USP, Brasil)

Prof. Dr. Alexandre Alves de Lima Ribeiro (IFSP, Brasil)

Prof. Dr. Alexsandro da Silva (UFPE, Brasil)

Prof. Dr. Aluizio Lendl Bezerra (UECE, Brasil)

Profa. Dra. Ana Claudia Balieiro Lodi (USP, Brasil)

Profa. Dra. Ana Lúcia Terra (IPP, Portugal)

Prof. Dr. Armando Terribili Filho (IMPARIAMO, Brasil)

Prof. Dr. Christian Fernando dos Santos Moura (IFSP, Brasil)

Profa. Dra. Cristina Bongestab (UEPB, Brasil)

Profa. Dra. Cristiane Navarrete Tolomei (UFMA, Brasil)

Prof. Dr. Dánie Marcelo de Jesus (UFMT, Brasil)

Profa. Dra. Divanize Carbonieri (UFMT, Brasil)

Prof. Dr. Eduardo Gomes Onofre (UEPB, Brasil)

Profa. Dra. Elda Firmo Braga (UERJ, Brasil)

Prof. Dr. Fernando Zolin-Vesz (UFMT, Brasil)

Profa. Dra. Gretel Eres Fernández (USP, Brasil) 
Prof. Dr. Helder Garmes (USP, Brasil)

Profa. Dra. Iraíde Marques de Freitas Barreiro (UNESP, Brasil)

Prof. Dr. José Alberto Miranda Poza (UFPE, Brasil)

Prof. Dr. José Joelson Pimentel de Almeida (UEPB, Brasil)

Prof. Dr. José Manuel Simões (Universidade de São José, Macau-China)

Prof. Dr. José Veranildo Lopes da Costa Junior (UERN, Brasil)

Profa. Dra. Kelly Cristiane Henschel Pobbe de Carvalho (UNESP, Brasil)

Profa. Dra. Kelli da Rosa Ribeiro (FURG, Brasil)

Prof. Dr. Kleber Aparecido da Silva (UNB, Brasil)

Profa. Dra. Laura Janaina Dias Amato (UNILA, Brasil)

Prof. Dr. Lidemberg Rocha de Oliveira (CODESE-SEEC/RN, Brasil)

Prof. Dr. Manassés Morais Xavier (UFCG, Brasil)

Profa. Dra. Maria de Fátima Almeida (UFPB, Brasil)

Profa. Dra. Maria de Lourdes Otero Brabo Cruz (UNESP, Brasil)

Profa. Dra. Maria Manuela Pinto (Universidade do Porto, Portugal)

Profa. Dra. Marta Lúcia Cabrera Kfouri-Kaneoya (UNESP, Brasil)

Prof. Dr. Marcelo José da Silva (UNESPAR, Brasil)

Prof. Dr. Marcelo Medeiros (UEPB, Brasil)

Profa. Dra. Michele Viviene Carbinatto (Escola de Educação Física e Esporte - USP, Brasil)

Prof. Dr. Nefatalin Gonçalves Neto (UFRPE, Brasil)

Prof. Dr. Pedro Farias Francelino (UFPB, Brasil)

Profa. Dra. Pricila Gunutzmann (UAM, Laureate Universities International, Brasil)

Profa. Dra. Renata Barbosa Vicente (UFRPE, Brasil)

Prof. Dr. Ronaldo Corrêa Gomes Junior (UFMG, Brasil)

Profa. Dra. Rosa Ana Martín Vegas (USAL, Espanha)

Profa. Dra. Rosangela de Araujo Lima (UNINASSAU, Brasil)

Prof. Dr. Samir Mustapha Ghaziri (Mentes Abertas, Brasil)

Profa. Dra. Selma de Cássia Martinelli (UNICAMP, Brasil)

Profa. Dra. Shirley Barbosa das Neves Porto (UFCG, Brasil)

Prof. Dra. Silvana Schwab do Nascimento (FURG, Brasil)

Profa. Dra. Simone Dália de Gusmão Aranha (UEPB, Brasil)

Prof. Dr. Thiago Barros (UFRGS, Brasil)

Profa. Dra. Véronique Le Dü da Silva-Semik (UNL, Portugal) 


\section{Editorial}

Open Minds International Journal (OMIJ) é a Revista Eletrônica da Editora Mentes Abertas que faz parte um coletivo plural e internacional, formado por profissionais de diversas áreas com o objetivo de apoiar o desenvolvimento de pessoas/pesquisadores através das publicações na área de Educação através da pesquisa, ensino e atividades de intercâmbio acadêmico e científico.

Lembramos que os estudos em Educação, Linguagens e Culturas em suas mais diversas áreas são sempre muito bem-vindos para publicação. Temos a convicção de que com a experiência de nossos especialistas e a colaboração de uma rede internacional integrada teremos uma Revista realmente de primeira linha.

Evidenciamos, mais uma vez, que os textos e conteúdos publicados na Open Minds International Journal são de total responsabilidade de seus autores e autoras, de maneira que qualquer problema ético ou legal deverá ser realizado diretamente ao respectivo autor ou autora da publicação por meio do e-mail identificado e disponibilizado no texto. Ademais, agradeço a todos os autores e autoras e demais envolvidos no processo de publicação.

Este ano de 2020 está marcado historicamente pela PANDEMIA da COVID-19 e pela "descrença" na Ciência e na Pesquisa Científica por parte de "alguns representantes políticos sem formação acadêmica ou indutor do quanto pior melhor". Na contramão dessas "aberrações insanas em pelo Século XXI" finalizamos o ano com o terceiro número da Open Minds International Journal com um Conto, três Resenhas (duas de livrso e uma de um documentário) e treze Artigos. As produções desta edição contemplam abordagens Bakhtinianas, Literárias, Estudos de Casos Escolares Institucionais, Estratégias de Tradução, Metodologias Ativas, Autonomia Docente, Fronteiras Histórico-Cognitivas na Interface Espanhol-Português, Metáforas na aprendizagem de Estudantes Universitários, Gerenciamento do Branding, Literatura Afro-americana e inclusão de alunos surdos, além de Revisões Críticas de livros e de um documentário, e, um Conto Literário.

Diante dessas produções temos a certeza que sempre haverá "resistência" acadêmica, intelectual e científica, para que a "sanidade humana" possa se perpetuar e incentivar para o bem as futuras gerações.

Apreciem, absorvam e divulguem as informações. Boas leituras!

Prof. Dr. Helder Neves de Albuquerque Editor Chefe 